\title{
Characterization of competitive interactions in the coexistence of Bt-transgenic and conventional rice
}

\author{
Yongbo Liu', Feng $\mathrm{Ge}^{2}$, Yuyong Liang ${ }^{3}$, Gang Wu${ }^{4}$ and Junsheng $\mathrm{Li}^{i^{*}}$
}

\begin{abstract}
Background: Transgene flow through pollen and seeds leads to transgenic volunteers and feral populations in the nature, and consumer choice and economic incentives determine whether transgenic crops will be cultivated in the field. Transgenic and non-transgenic plants are likely to coexist in the field and natural habitats, but their competitive interactions are not well understood.

Methods: Field experiments were conducted in an agricultural ecosystem with insecticide spraying and a natural ecosystem, using Bt-transgenic rice (Oryza sativa) and its non-transgenic counterpart in pure and mixed stands with a replacement series.

Results: Insect damage and competition significantly decreased plant growth and reproduction under the coexistence of transgenic and conventional rice. Insect-resistant transgenic rice was not competitively superior to its counterpart under different densities in both agricultural and natural ecosystems, irrespective of insect infection. Fitness cost due to Bt-transgene expression occurred only in an agroecosystem, where the population yield decreased with increasing percentage of transgenic rice. The population yield fluctuated in a natural ecosystem, with slight differences among pure and mixed stands under plant competition or insect pressure. The presence of Chilo suppressalis infection increased the number of non-target insects.

Conclusions: Plant growth and reproduction patterns, relative competition ability and population yield indicate that Bt-transgenic and non-transgenic rice can coexist in agroecosystems, whereas in more natural habitats, transgenic rice is likely to outcompete non-transgenic rice.
\end{abstract}

Keywords: Coexistence, Transgenic rice, Competitive ability, Herbivory, Agricultural ecosystem, Natural ecosystem

\section{Background}

As genetically modified (GM) crops have been cultivated worldwide, concerns over ecological consequences emerge because transgenic crops can establish a feral populations in the natural habitat [1-5], which might lead to coexistence with or even extinction of local species. The adventitious presence of GM material in non-GM crops is also a concern due to its economic implications. Without regulations, farmers can grow either GM or GM-free plants in their fields. The coexistence of GM and conventional crops depends on choices by farmers, which is influenced by consumer choice and economic incentives [6,7]. Proper isolation distance or pollen barriers between GM and non-GM fields should be

\footnotetext{
* Correspondence: liu.yongbo@yahoo.com; lijsh@craes.org.cn

${ }^{1}$ State Key Laboratory of Environmental Criteria and Risk Assessment, Chinese Research Academy of Environmental Sciences, Beijing 100012, China Full list of author information is available at the end of the article
}

ensured to minimize cross-fertilization so that the adventitious presence of transgenic materials in conventional products will be kept below the legal tolerance threshold, e.g. $0.9 \%$ in European Union (Commission Recommendation, 2003). To prevent insects from developing resistance to transgenic crops, the refuge strategy, where transgenic and non-transgenic crops coexist with each other, has usually been adopted $[8,9]$. Thus, transgenes might exist in landraces and wild relatives through gene flow and introgression by pollen dispersal $[1-5,10]$ or seed movement $[11,12]$. Therefore, transgenic plants might coexist with non-transgenic plants in and out of the fields [3,7,13-16].

Transgenic crops are usually resistant to pests, herbicides, or diseases, which might enhance their fitness and promote the spread of transgenes into natural populations [17]. In mixture stands, however, the persistence of transgenic 
plants in a population depends on their relative fitness and competitive ability against non-transgenic neighbors. In general, insect-resistant plants have a competitive advantage and enhanced fecundity, particularly under high insect pressure [18-22]. Commercialization of Bt-transgenic crops, however, could reduce the abundance of target insects in agroecosystem [23,24]. This might influence the plant and insect relationship and the frequency of insect-resistant transgenic plants in mixed populations, which determines ecological risks and monitoring strategies [2].

Previous studies have been mainly focused on gene flow from transgenic crops to landraces and wild relatives and the coexistence of transgenic and non-transgenic progeny $[1,3,20,22]$. The long-term coexistence of transgenic and non-transgenic crops, however, has been largely ignored $[15,25,26]$. Moreover, ecological risk of crop-crop gene flow might be higher than that of crop-wild gene flow because no cross barrier exists between intraspecies crops. For example, pollen flow between transgenic and nontransgenic oilseed rapes (Brassica napus) results in the resistance of certain plants to three herbicides in the field [15].

GM rice (Oryza sativa) conferring insect-resistance, herbicide-tolerance, and high grain quality has been extensively developed in China [27], and two insect-resistant rice lines with $B t$ (Bacillus thuringiensis) transgenes were granted biosafety certificates in 2009. Thus, GM and nonGM rice are likely to coexist after the commercialization of GM crops, which might become a major concern over biosafety. This study aims to test (1) the relative competitive ability of insect-resistant $B t$-transgenic to nontransgenic rice with different proportions of the former in mixed stands, (2) whether competition and herbivory pressures affect relative performance of $B t$-transgenic to nontransgenic rice in pure and mixture stands, (3) whether increased frequency of transgenic plants in a population alters population productivity. The experiments were carried out in two settings: an agricultural ecosystem with insecticide spraying under local farming practice and a simulated natural ecosystem without insecticide use or other human disturbances.

\section{Results}

\section{Plant growth and reproduction of transgenic and} conventional rice

Overall, rice plants performed better in the agriculturally managed site, Wuhan, than that in the natural site, Nanchang. Plants in Wuhan site grew higher and produced $20 \%$ more valid tillers, $60 \%$ more biomass, $50 \%$ more viable seeds and $80 \%$ more seed weight per plant on average and had a lower rate of invalid tillers and hollow seeds than that in Nanchang (Figure 1). Thus, subsequent analysis was conducted for Wuhan and Nanchang sites respectively.
Herbivory damage and plant competition significantly decreased plant growth and reproduction. In Wuhan, infection decreased plant height and seed weight and increased the rate of invalid tillers (RIT), but it had little effect on other characteristics (Table 1, Figure 1). Plant height, tiller number, biomass and ear length were not significantly different among five percentages of Bt-transgenic rice (Oryza sativa) Huahui-1 (HH), but the number of hollow seeds increased and seed weight and reproductive allocation (RA) decreased with increasing $\mathrm{HH}$ percentage (Table 1, Figure 2). The fitness parameters in high density plots, except for RIT, were significantly lower than that of plants in low density plots (Table 1). There was a significant interaction between infection and density for RIT and seed weight (Table 1). Insect pressure and plant competition had effects on plant growth and reproduction (Figure 1). Compared to non-transgenic Minghui-63 (MH), transgenic rice $\mathrm{HH}$ had more valid tillers and hollow seeds, lower RIT, less viable seeds and smaller seed weight (Table 1). There was significant interaction between plant type and infection for predicting RA; between $\mathrm{HH}$ percentage and plant type for predicting biomass and seed weight; between plant type and density for predicting RIT, seed weight and RA, respectively (Table 1).

The increased frequency of transgenic rice had little effect on rice growth and reproduction. In the Nanchang site, as the percentage of transgenic plants increased, plants did not show significant difference in any variable (Table 2, Figure 2). Infection increased RIT and the number of hollow seeds and decreased seed weight and RA, but had little effect on other characteristics (Table 2, Figure 1). The plant fitness parameters in high density plots, except for RIT, were significantly lower than that of the plants in low density plots (Table 2). There was significant interaction between infection and density for RIT and seed weight. Insect pressure and plant competition had additive effects on plant growth and reproduction (Figure 1). There was little difference in the performance of $\mathrm{HH}$ and $\mathrm{MH}$ in the natural ecosystem (Table 2). Little interaction occurred among infection, percentage, density and plant type, except between percentage of transgenic plants and plant type for RIT and hollow seeds, and between density and plant type for biomass (Table 2).

\section{Relative competitive ability of insect-resistant rice to conventional rice}

There was little difference in competitive ability between $B t$-transgenic and conventional rice. The relative difference (RD) between $\mathrm{HH}$ and $\mathrm{MH}$ did not significantly differ from $0(\mathrm{P}>0.05, t$-test $)$ under three densities $(0.30 \mathrm{~m}, 0.20 \mathrm{~m}$ and $0.10 \mathrm{~m}$ space) in the two insect experiments of Wuhan and Nanchang sites. The (relative 

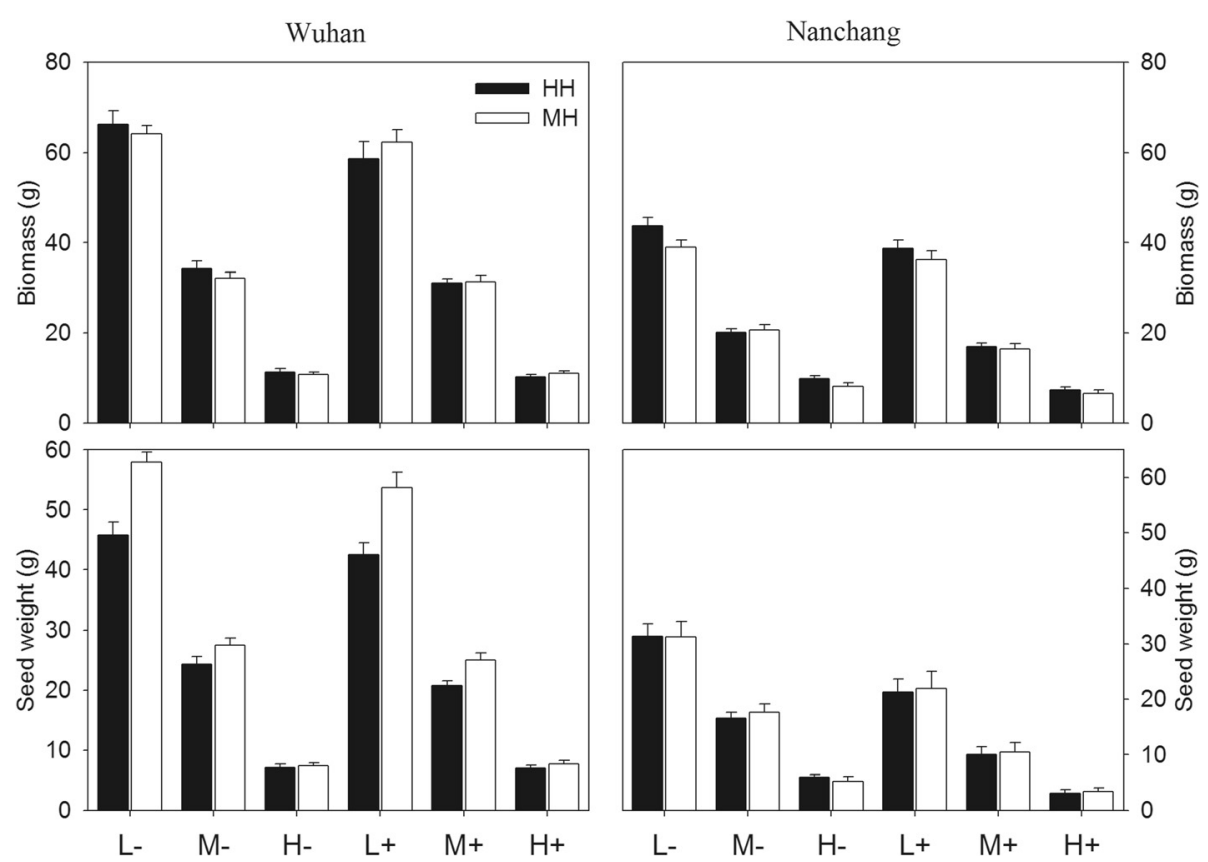

Figure 1 Biomass and seed weight of rice plants in Wuhan and Nanchang sites. Black bars, HH plants; white bars, MH plants. L, M, and H indicate low, medium and high densities respectively. " + " and " " "indicate the presence and absence of infection. Vertical bars denote SEM. See Table 2 for statistical significance.

competitive ability) RCC values did not significantly deviate from 1 ( $\mathrm{P}>0.05, t$-test) under three densities for biomass and seed production, with or without insects (Table 3), suggesting that $\mathrm{HH}$ rice was not competitively superior to $\mathrm{MH}$ plants in the mixed stands.
Plot production under the coexistence of transgenic and conventional rice

Plot production for biomass and seed weight was lower in the Nanchang site than that in the Wuhan site. The variation of population yield among different percentages of

Table 1 Effect estimates and degrees of freedom of split-plot ANOVA for plant vegetation and reproductive growth in Wuhan site

\begin{tabular}{|c|c|c|c|c|c|c|c|c|}
\hline & DF & $\mathrm{RIT}^{\mathrm{a}}$ & Biomass & Ear length & Viable seeds & Hollow seeds & Seed weight & $\mathrm{RA}^{\mathrm{a}}$ \\
\hline Infection (I) & 1 & $41.9^{*}$ & 3.60 & 3.59 & 2.28 & 0.44 & $24.6^{*}$ & 0.05 \\
\hline Percentage(P) & 4 & 1.19 & 0.97 & 0.34 & 1.50 & $5.26^{* *}$ & $4.40^{*}$ & $3.48^{*}$ \\
\hline$I \times P$ & 4 & 0.73 & 0.65 & 0.10 & 0.92 & 0.85 & 1.14 & 0.21 \\
\hline Density (D) & 2 & $51.9^{* * *}$ & $1219^{* * *}$ & $92.7^{* * *}$ & $34.4^{* * *}$ & $42.2^{* * *}$ & $1710^{* * *}$ & $22.5^{* * *}$ \\
\hline$I \times D$ & 2 & $4.44^{*}$ & 2.18 & 1.49 & 0.75 & 0.24 & $3.90^{*}$ & 2.72 \\
\hline$P \times D$ & 8 & 0.58 & 1.05 & 1.28 & 0.54 & 1.83 & $2.23^{*}$ & 1.80 \\
\hline$I \times P \times D$ & 8 & 0.46 & 0.56 & 0.52 & 0.68 & 0.37 & 2.03 & 1.36 \\
\hline Plant type (T) & 1 & $24.6^{* * *}$ & 0.00 & 0.30 & $19.9^{* * *}$ & $64.4^{* * *}$ & $29.8^{* * *}$ & $107^{* * *}$ \\
\hline$I \times T$ & 1 & 0.04 & 3.10 & 0.01 & 0.01 & 0.16 & 0.27 & $5.88^{*}$ \\
\hline$P \times T$ & 2 & 0.31 & $3.38^{*}$ & 0.87 & 1.23 & 0.20 & $4.54^{*}$ & 0.59 \\
\hline$D \times T$ & 2 & $3.63^{*}$ & 0.30 & 0.15 & 2.31 & 1.97 & $14.7^{* * *}$ & $11.8^{* * *}$ \\
\hline$I \times P \times T$ & 2 & 0.47 & 0.24 & 0.03 & 0.06 & 0.03 & 0.56 & 0.04 \\
\hline$I \times D \times T$ & 2 & 3.07 & 0.35 & 1.83 & 1.12 & 0.25 & 0.24 & 0.66 \\
\hline$P \times D \times T$ & 4 & 2.46 & 0.53 & 1.31 & 0.38 & 0.16 & 0.59 & 0.61 \\
\hline$I \times P \times D \times T$ & 4 & 1.12 & 0.47 & 0.81 & 0.99 & 1.39 & 0.76 & 0.79 \\
\hline
\end{tabular}

${ }^{*},{ }^{* *}$ and ${ }^{* * *}$ indicate significant difference at the $\mathrm{P}<0.05, \mathrm{P}<0.01$ and $\mathrm{P}<0.001$ levels.

${ }^{\mathrm{a}} \mathrm{RIT}$, indicates the rate of invalid tillers; RA, reproductive allocation. 


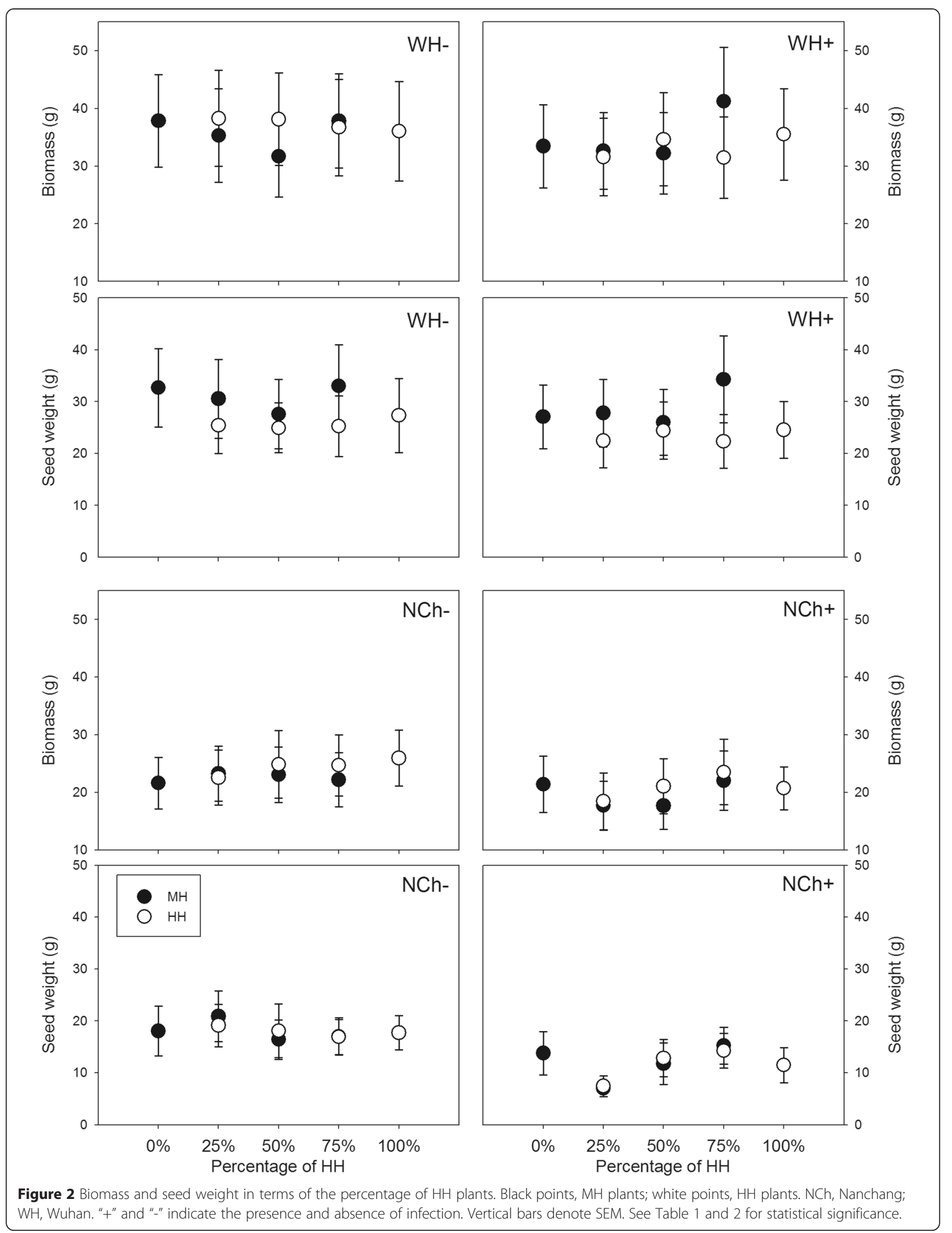


Table 2 Effect estimates and degrees of freedom of split-plot ANOVA for plant vegetation and reproductive growth in Nanchang site

\begin{tabular}{|c|c|c|c|c|c|c|c|c|}
\hline & DF & $\mathrm{RIT}^{\mathrm{a}}$ & Biomass & Ear length & Viable seeds & Hollow seeds & Seed weight & $\mathrm{RA}^{\mathrm{a}}$ \\
\hline Infection (I) & 1 & $30.1^{*}$ & 4.44 & 16.7 & 2.54 & $75.6^{*}$ & $26.0^{*}$ & $148^{* *}$ \\
\hline Percentage $(\mathrm{P})$ & 4 & 1.35 & 1.31 & 2.17 & 0.61 & 1.86 & 0.33 & 0.62 \\
\hline$I \times P$ & 4 & 1.63 & 1.25 & 1.28 & 1.43 & 0.96 & 1.64 & 1.60 \\
\hline Density (D) & 2 & $317^{* * *}$ & $873^{* * * *}$ & $55.1^{* * *}$ & $28.6^{* * *}$ & $17.4^{* * *}$ & $239^{* * *}$ & $23.8^{* * *}$ \\
\hline $1 \times D$ & 2 & $17.2^{* * * *}$ & 0.91 & 1.70 & 0.31 & 0.01 & $6.78^{* *}$ & 0.99 \\
\hline$P \times D$ & 8 & 1.70 & 1.12 & 1.90 & 1.75 & 0.61 & 1.11 & 0.91 \\
\hline$I \times P \times D$ & 8 & $2.68^{*}$ & 1.44 & $2.23^{*}$ & 0.63 & 1.96 & 1.35 & 0.90 \\
\hline Plant type (T) & 1 & 0.19 & 3.46 & 0.01 & 2.25 & 3.05 & 0.01 & 0.43 \\
\hline$I \times T$ & 1 & 0.00 & 0.17 & 1.97 & 3.59 & 1.30 & 0.03 & 0.05 \\
\hline$P \times T$ & 2 & $5.56^{* *}$ & 0.89 & 2.72 & 2.88 & $4.38^{*}$ & 0.78 & 1.19 \\
\hline $\mathrm{D} \times \mathrm{T}$ & 2 & 1.08 & $3.32^{*}$ & 0.08 & 1.07 & 1.34 & 0.08 & 1.30 \\
\hline$I \times P \times T$ & 2 & 0.33 & 0.27 & 2.27 & 0.36 & $4.21^{*}$ & 0.44 & 0.10 \\
\hline$I \times D \times T$ & 2 & 0.06 & 0.05 & 1.55 & 1.09 & 1.74 & 0.20 & 0.72 \\
\hline$P \times D \times T$ & 4 & 0.92 & 0.46 & 0.46 & 0.43 & 0.19 & 0.96 & 0.09 \\
\hline$I \times P \times D \times T$ & 4 & 1.32 & 0.31 & 0.27 & 0.43 & 0.52 & 1.39 & 1.22 \\
\hline
\end{tabular}

${ }^{*},{ }^{* *}$ and ${ }^{* * *}$ indicate significant difference at the $\mathrm{P}<0.05, \mathrm{P}<0.01$ and $\mathrm{P}<0.001$ levels.

${ }^{\mathrm{a}} \mathrm{RIT}$, indicates the rate of invalid tillers; RA, reproductive allocation.

$\mathrm{HH}$ was higher in the Nanchang site than that in the Wuhan site (Figures 3,4), suggesting that the population in the natural habitat was more dynamic than that in the habitat under human control, for both transgenic and nontransgenic rice.

Overall plot productivity biomass did not vary among different percentages of transgenic rice in the plots. The plot-level analysis showed little difference among pure plots and mixtures of the $\mathrm{HH}$ and $\mathrm{MH}$ plants for total biomass in Wuhan and Nanchang and for seed weight in Nanchang (Table 4; Figures 3, 4;). Total seed weight per plot decreased with increasing percentage of $\mathrm{HH}$ in Wuhan site (Table 4, Figure 3). Overall performance per plot including all the $\mathrm{HH}$ and $\mathrm{MH}$ plants was higher in low density than in high density (Table 4). Infection significantly decreased total seed weight of all the $\mathrm{HH}$ and $\mathrm{MH}$ plants per plot in the two sites, but had little effect on total biomass (Table 4). The insect damage and plant competition between transgenic and non-transgenic rice showed an additive effect on population production. A significant interaction existed between infection and density for the total seed weight in the two sites and the biomass in Wuhan site. Little interaction, however, was found among infection, $\mathrm{HH}$ percentage and density, except for seed weight in Wuhan (Table 4).

\section{Insect survival under the coexistence of transgenic and conventional rice}

The coexistence of transgenic and conventional rice had little effect on non-target insects in the simulated natural environment. There were more insects in infected plots than in the plots without infection in the Nanchang site, i.e., 29.5 vs. 10.6 planthoppers per two plants on average and $5.0 v s$. 2.4 spiders per two plants on average (Figure 5 ). The number of planthoppers and spiders and the rate of infected plants by Chilo suppressalis (RPW) did not differ significantly among different percentages of $\mathrm{HH}$. The RPW decreased with the increased percentage of $\mathrm{HH}$ plants in the plots without infection.

Table 3 Mean ( \pm SD) of relative crowding coefficient $(\mathrm{RCC})$ between Bt-transgenic and conventional rice

\begin{tabular}{|c|c|c|c|c|c|}
\hline \multirow[t]{2}{*}{ Infection } & \multirow[t]{2}{*}{ Density } & \multicolumn{2}{|l|}{ Wuhan } & \multicolumn{2}{|l|}{ Nanchang } \\
\hline & & Biomass & Seed weight & Biomass & Seed weight \\
\hline \multirow[t]{3}{*}{ No } & Low & $1.11 \pm 0.05$ & $1.33 \pm 0.34$ & $0.96 \pm 0.24$ & $1.10 \pm 0.67$ \\
\hline & Medium & $1.02 \pm 0.06$ & $0.94 \pm 0.23$ & $0.94 \pm 0.26$ & $1.03 \pm 0.50$ \\
\hline & High & $1.04 \pm 0.09$ & $1.08 \pm 0.45$ & $0.67 \pm 0.24$ & $1.14 \pm 0.87$ \\
\hline \multirow[t]{3}{*}{ Yes } & Low & $1.02 \pm 0.04$ & $1.15 \pm 0.49$ & $1.39 \pm 0.42$ & $1.25 \pm 0.40$ \\
\hline & Medium & $0.98 \pm 0.03$ & $0.89 \pm 0.21$ & $0.94 \pm 0.32$ & $1.43 \pm 0.41$ \\
\hline & High & $1.02 \pm 0.06$ & $0.87 \pm 0.28$ & $0.94 \pm 0.51$ & $1.34 \pm 0.66$ \\
\hline
\end{tabular}




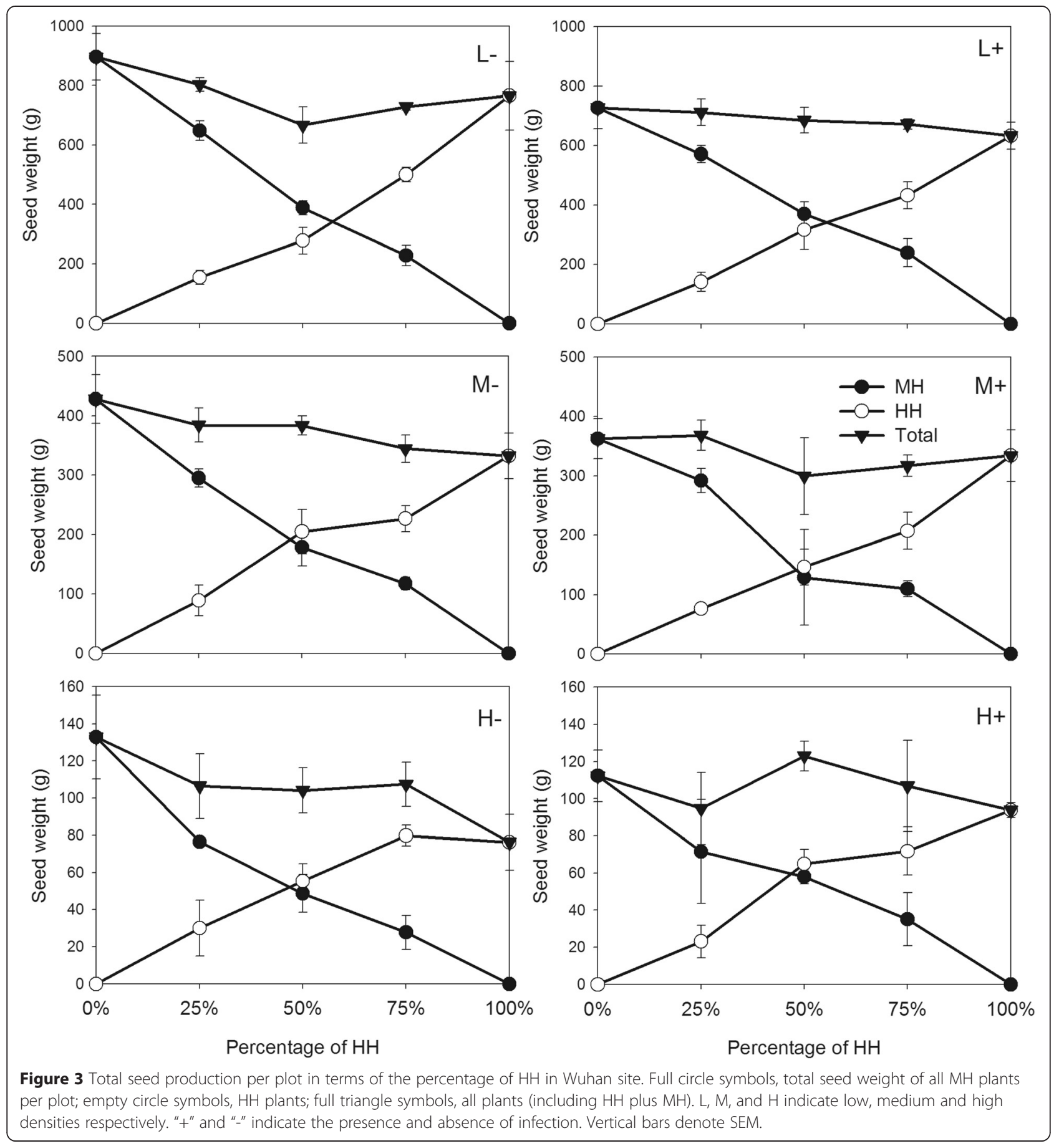

\section{Discussion}

Effects of coexistence on plant growth and reproduction

The coexistence of transgenic and conventional rice has an effect on plant growth and reproduction, which depends on the local environment, herbivory festation and competition. In the agricultural ecosystem with insecticides to control non-targeted insects (Wuhan site), transgenic rice produced more aborted seeds and less viable seeds than non-transgenic plants. No difference of aborted and viable seeds was observed between transgenic and non-transgenic plants in the natural ecosystem, where nontargeted insects existed without insecticide application (Nanchang site). In another study, transgenic MH86 (a restorer line) with $B t / C P T I$ showed a yield loss in comparison with its non- $B t$ counterpart under low insect pressure $[28,29]$, but little yield differences were observed between cry $1 A b / c$ Bt-Shanyou63 (a hybrid variety) and its non- $B t$ counterpart [30,31]. Wang et al. [32] found Bt-transgenic 


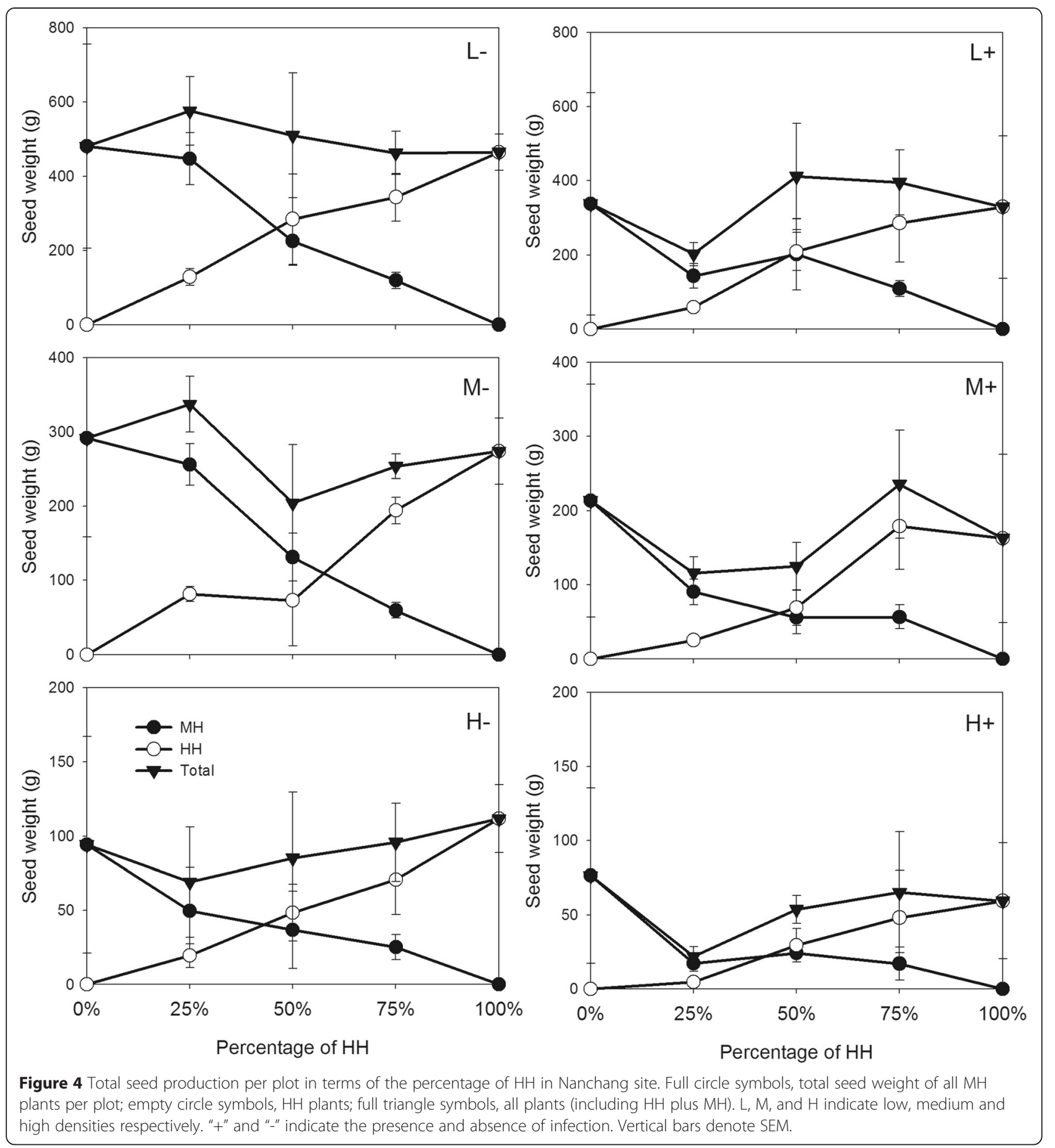

Minghui63 with $c r y 2 A$ and $c r y 1 C$ had lower grain yield than Minghui63. They held that this yield loss was correlated with reduced grain filling percentage resulting from reduction of growth-promoting phytohormones. An alternative explanation is the fitness cost of expressing $B t$ transgene in the absence of insects, which has been shown in rice [29] and rice hybrids [20]. No fitness cost of expressing
$B t$ transgene in the absence of selection pressure was detected in Brassica [18,33], in sunflower or in rice [21].

As shown in this study, herbivory has a negative effect on plant growth and reproduction [34,35]. Certain studies, however, show little effect of herbivory on plant performance because of compensatory growth [36,37]. Here, insect damage (Chilo suppressalis) decreased seed weight but 
Table 4 Split-plot ANOVA for total biomass and seed weight per plot in Wuhan and Nanchang sites

\begin{tabular}{|c|c|c|c|c|c|}
\hline & \multirow[b]{2}{*}{ DF } & \multicolumn{2}{|l|}{ Wuhan } & \multicolumn{2}{|c|}{ Nanchang } \\
\hline & & Biomass & Seed weight & Biomass & Seed weight \\
\hline Infection (I) & 1 & 5.70 & $249^{* *}$ & 4.84 & $20.8^{*}$ \\
\hline Percentage $(P)$ & 4 & 0.43 & $6.60^{* *}$ & 1.45 & 0.17 \\
\hline$I \times P$ & 4 & 0.38 & 1.61 & 1. 25 & 1.15 \\
\hline Density (D) & 2 & $1379^{* * *}$ & $1943^{* * *}$ & $729^{* * *}$ & $147^{* * *}$ \\
\hline$I \times D$ & 2 & $3.64^{*}$ & $7.66^{*}$ & 1.11 & $5.08^{*}$ \\
\hline$P \times D$ & 8 & 1.07 & 2.11 & 1.31 & 0.90 \\
\hline$I \times P \times D$ & 8 & 0.51 & $2.28^{*}$ & 1.31 & 0.86 \\
\hline
\end{tabular}

had little effect on seed number. Vaughton and Ramsey also found that defoliation reduced seed mass but not seed number [38]. Insect infection increased the number of aborted seeds in the natural ecosystem, in accordance with previous results that foliar herbivory increased the rate of aborted seeds while floral herbivory decreased it [39].

Plant density, representing competition intensity, significantly reduced the production of both GM and non-GM rice. Competition and herbivory had an additive effect on plant performance, as shown in other reports $[2,40]$. The interaction could be antagonistic because the impacts of herbivory on neighbors could decrease competition from neighbors [41,42]. There might be no interaction if the disadvantage of the susceptible plants failed to correlate with the specific or combined pressure from competition and herbivory [43].

\section{Relative competitive ability}

Theoretically, plants harboring the $B t$ gene are expected to display insect-resistance and less herbivore damage, leading to greater competitive ability than insect-susceptible plants $[18,19,21,44]$. In this study, however, both RD and RCC values showed that $B t$-transgenic rice failed to display competition advantage compared with non-transgenic rice. This is in agreement with other reports. For example, Chen et al. (2006) found no competition advantage of Bt-transgenic rice to control lines because of yield losses in transgenic rice [28].

There are four possible explanations for our failure to observe competitive advantage of $B t$-transgenic rice. The first is the fitness cost of expressing $B t$ transgene discussed above. The second is that more non-target insects were observed in infected cages than in control cages. Bt-transgenic rice resisted to target insects but not to non-target insects (e.g. planthoppers), which affected the growth of $B t$-transgenic rice. Thirdly, the presence of transgenic plants could protect non-transgenic plants, a "halo effect" proposed by Alstad \& Andow [45] and observed in other reports [23,24]. Hutchison et al. [24] found that non-Bt corn was protected by the adjacent $B t$ corn from being damaged, resulting in billions of

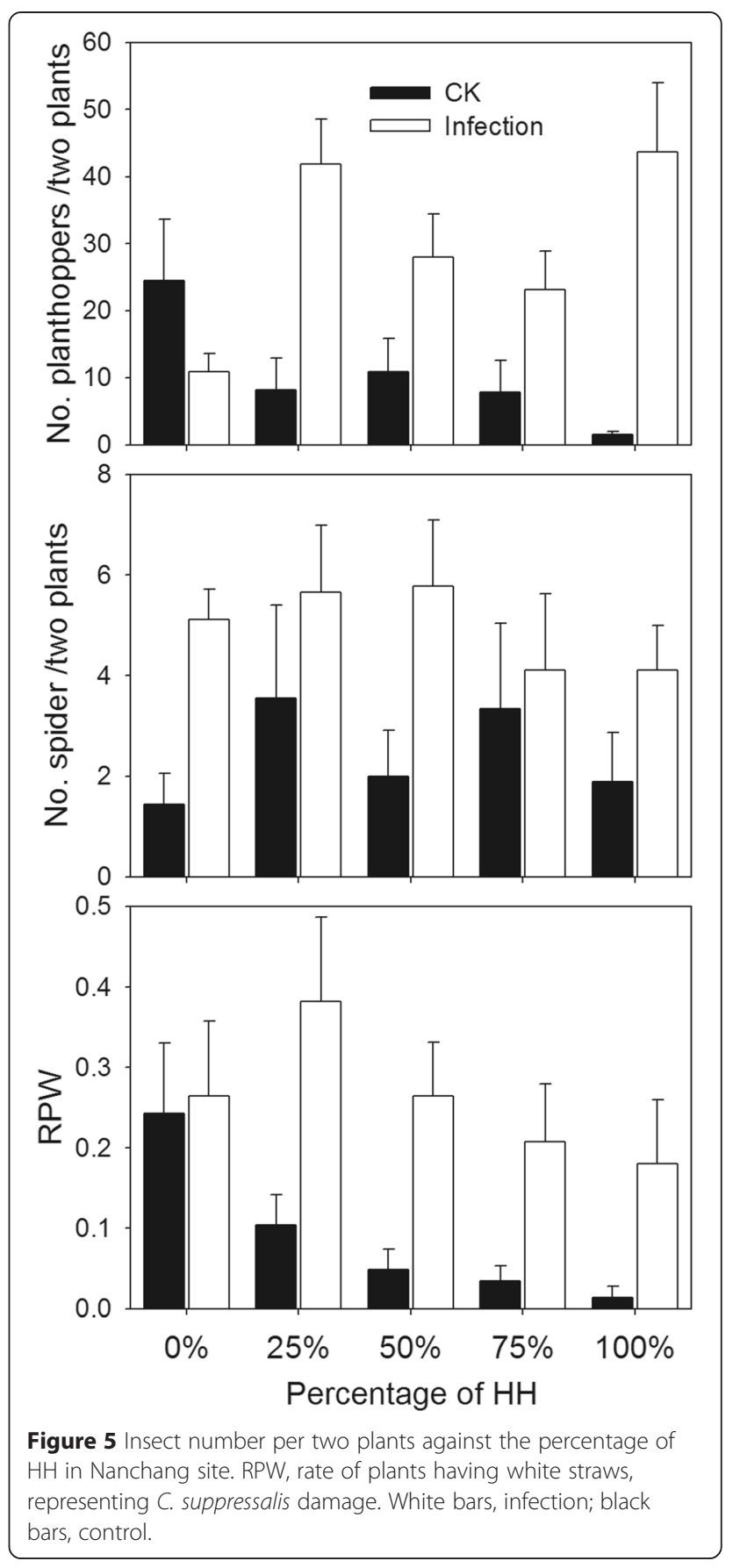

dollars of economic benefits for the United States over 14 years. Bt cotton has been cultivated over 10 years in Northern China, significantly decreasing the number of target insects (cotton bollworm, Helicoverpa armigera) on $B t$ cotton, non- $B t$ cotton and other host crops $[23,46]$. Fourthly, the relative competitiveness of insect-resistant plants to conventional plants depends on access to resources and allocation strategy. At Nanchang site, insect infection led to an increase in resources allocation to herbivory defence (including non-target insects), resulting in low production. Resistant 
plants have better access to resources (including light, water, nutrient) than the susceptible counterpart because the former suffers less damage. However, there is a trade-off between resistance capacity and competitive ability for plants e.g. [40], since the allocation of resources to defence will decrease plant growth [47]. Kalinina et al. found that transgenic wheat resistant to powdery mildew was inferior to its non-transgenic counterpart in competition even with the presence of the pathogen, since transgenic wheat reduced yield and seed number under competition compared with its control [48].

\section{Population yield in the coexistence of transgenic and conventional rice}

Since volunteer plants could persist in or outside of cultivation through pollen-mediated gene flow or seed movement of transgenic plants [10-12], it seems inevitable that transgenic and non-transgenic plants would coexist in the field and natural habitats $[3,7,13-16]$. One concern of the coexistence is the shift from a susceptible population to a resistant one irrespective of insects e.g. [18].

$B t$-transgenic rice failed to show competition advantage compared with non-transgenic rice in the present study. This would hamper the increased frequency of Bt-transgenic rice and encourage coexistence of transgenic and non-transgenic plants in mixed populations. In the Wuhan site, total seed weight per plot decreased with increased percentage of transgenic rice, due to the fitness cost of expressing $B t$ gene as discussed above. In an experiment to simulate insect-susceptible plants by mechanical wounding, the increase of healthy plants in a population of damaged plants did not increase the population productivity [2].

However, high fluctuation of population production in the natural ecosystem (Nanchang site) suggests its vulnerability, which might lead to a shift from non-transgenic to transgenic population and vice versa. Previous studies found that transgenic plants were more likely to invade a harsh environment $[44,49]$. The commercial planting of transgenic crops has increased non-target insects in the fields $[23,46]$. Such insect infestation is ubiquitous in natural habitats, which might facilitate the spread of insect-resistant transgenes. In this study, planthoppers increased when target insects (C. suppressalis) occurred, explaining high fluctuation of population production. In addition, rice volunteers frequently appear in the wastelands, orchards or other habitats near fields because of seed movement or seedlings dispersal during the farming. Thus, it is likely that cultivated transgenic rice establishes feral populations as a type of weedy rice if the transgene could persist in the nature over time.

\section{Conclusions}

Considering the results of plant growth and reproduction, relative competitive ability and population yield, it is likely that the $B t$-transgenic and non-transgenic rice will coexist in agricultural ecosystems when commercial release of transgenic crops is permitted. A population in natural habitats is also possible to shift from non-transgenic to transgenic plants. The agricultural benefits and population productivity in diverse cultivation systems with coexisting GM and non-GM crops have been addressed $[7,14]$. Coexistence allows crop growers and consumers to produce or purchase conventional, organic or GM crops. In addition, as gene flow occurs naturally through pollen or seed flow, a transgenic crop may establish a feral population or volunteers that persist in natural ecosystems, such as oilseed rape, maize, flax and rice $[4,10,11,15,25,44]$. To mitigate the adventitious presence of GM plants caused by gene flow, strategies based on breeding, agronomic or molecular methods have been proposed e.g. [50]. The evaluation of the ecological consequences of ex post coexistence with GM plants, particularly in the natural ecosystem, is essential to construct sound regulations to reduce the adventitious presence of GM plants in agroecosystem and the invasion of transgenes in natural ecosystems.

\section{Methods}

\section{Plant material}

Bt-transgenic rice (Oryza sativa) Huahui-1 (HH) was granted a biosafety certificate in 2009 . HH and its nontransgenic counterpart Minghui-63 (MH), donated by Prof. Y. Lin from Huazhong Agricultural University, were employed in this study. $B t$-transgenic rice Huahui- 1 conferred a fusion gene Cry $1 \mathrm{Ab} / \mathrm{Cry} 1 \mathrm{Ac}$ driven by actin-I promoter [30]. The expression of $B t$ toxin protein in $120 \mathrm{HH}$ seeds was confirmed with PCR and enzyme-linked immunosorbent assay (ELISA) before sowing.

\section{Field trial}

Bt-transgenic rice Huahui-1 $(\mathrm{HH})$ and its counterpart Minghui-63 (MH) were sown in the fields. Rice seedlings were then transplanted into cages $(3 \mathrm{~m}$ width $\times 3 \mathrm{~m}$ length $\times 2.5 \mathrm{~m}$ height, protected by a $2 \mathrm{~mm}$-mesh nylon net), each cage containing three plots $(6 \times 6=36$ plants per plot) with three densities: $0.30 \mathrm{~m}, 0.20 \mathrm{~m}$ and $0.10 \mathrm{~m}$ row spacing (Figure 6). There were thirty cages in total in five rows and six columns, and three-meter space was set between the cages to ensure the plants' access to sunlight. To simulate the colonization process of insect-resistant plants into a non-transgenic population, five percentages of $\mathrm{HH}$ were added to plots in a replacement series: $0\left(\mathrm{~T}_{0}\right), 25 \%$ $\left(\mathrm{T}_{25}\right), 50 \%\left(\mathrm{~T}_{50}\right), 75 \%\left(\mathrm{~T}_{75}\right)$, and $100 \%$ of $\mathrm{HH}\left(\mathrm{T}_{100}\right)$. The five percentages were placed randomly in a column (Figure 6). Plant types ( $\mathrm{HH}$ or $\mathrm{MH}$ ) were placed randomly in each plot, ensuring the same ratio of $\mathrm{MH}$ to $\mathrm{HH}$ for the 16 plants in the center and the 20 plants at the border. Thirty cages were separated into three blocks, with one 


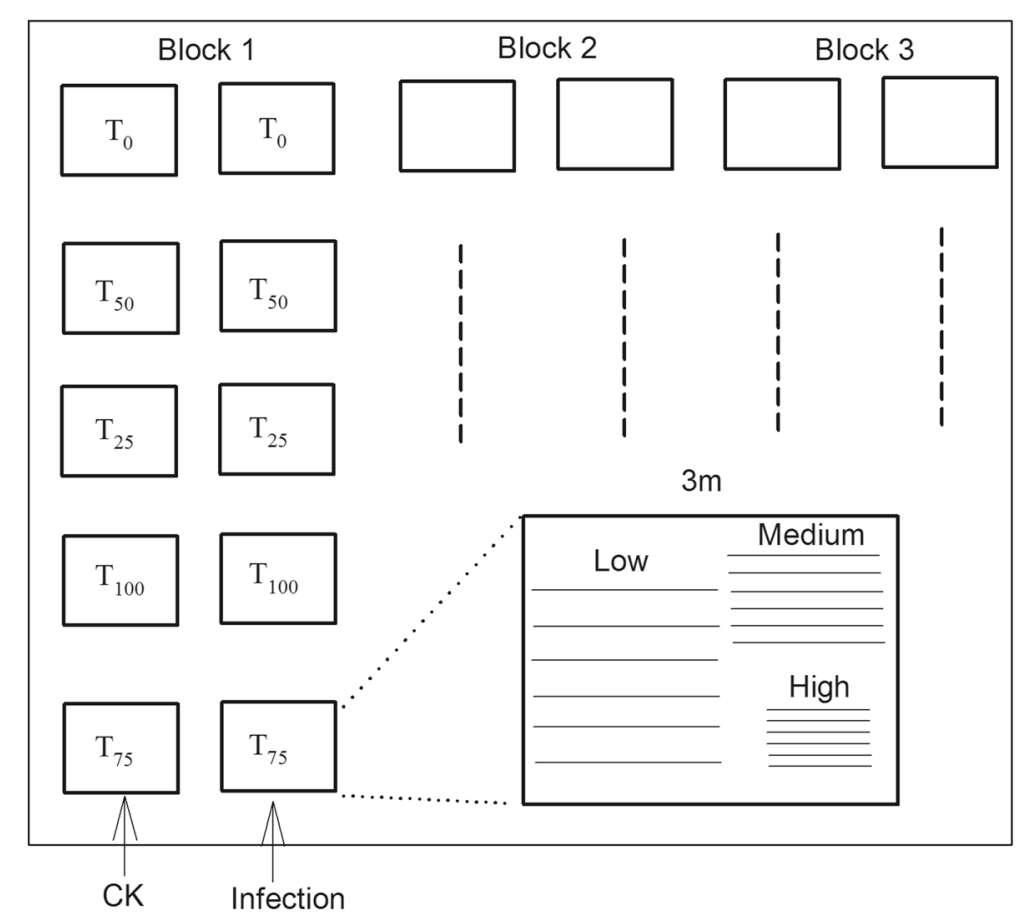

Figure 6 The map of the infection experiments in Wuhan and Nanchang sites. Infection, insect release of C. suppressalis; CK, without insect release. Low, medium and high densities with $0.3,0.2$ and $0.1 \mathrm{~m}$ space between plants. $T_{0}, T_{25}, T_{50}, T_{75}$ and $T_{100}$ indicate the percentages of transgenic rice.

column of cages infected by insects per block (Figure 6). Two second-instar larvae of Chilo suppressalis [Walker] were introduced to each plant.

The experiments were carried out at two sites, a transgenic rice research base of Huazhong Agricultural University, Wuhan, Hubei province (N30 $27^{\prime} 58.8^{\prime \prime}$, E114 $\left.21^{\prime} 45.8^{\prime \prime}\right)$, and a transgenic rice research base of Jiangxi Academy of Agricultural Sciences, Nanchang, Jiangxi province (N28 $21^{\prime} 91.4^{\prime \prime}$, E115 $\left.55^{\prime} 49.7^{\prime \prime}\right)$. The annual mean temperature and precipitation were $18.0^{\circ} \mathrm{C}$ and $2059 \mathrm{~mm}$ in Nanchang and $15.5^{\circ} \mathrm{C}$ and $1416 \mathrm{~mm}$ in Wuhan city in 2012 (China Statistical Yearbook). Rice seeds were sown in the fields on June 12, 2012 at Wuhan site and on June 5, 2012 at Nanchang site. The seedlings were transplanted in the fields after 28-30 days. After the seedlings survived, second-instar larvae of C. suppressalis were introduced to the plants. The site at Wuhan was considered as an agricultural ecosystem, with weeds removal by hands and insecticide spraying. Insecticide ( $22 \%$ a.i. buprofezin in 1000 -fold dilution, $450 \mathrm{~g} \mathrm{ha}^{-1}$ ) was applied twice (at the third and sixth week after infection) to control rice planthoppers in infected cages during the growing season. Simultaneously, avermectin $\left(1.8 \mathrm{~g} \mathrm{~L}^{-1}\right.$ a.i. in 1000 -fold dilution, $\left.2.5 \mathrm{~L} \mathrm{ha}^{-1}\right)$ and triazophos (20\% a.i. in 1000-fold dilution, $1500 \mathrm{~g} \mathrm{ha}^{-1}$ ) for C. suppressalis were applied twice in the cages without infection. The site at Nanchang simulated a natural ecosystem, without insecticide spraying or weed removal in the cages during the growing season. Fertilization and irrigation was implemented whenever need according to local agricultural farming.

\section{Measurements}

Plant height, number of valid tillers, the rate of invalid tillers (dead tillers plus tillers without ears) to all tillers per plant (RIT), biomass (straw weight after being insolated ten days) and seed weight per plant were measured for all 16 plants ( $\mathrm{HH}$ and/or $\mathrm{MH})$ in the center of each plot. Reproductive allocation (RA) per plant was defined by dividing seed weight with the biomass. Six ears were chosen randomly for each plant type ( $\mathrm{HH} v s . \mathrm{MH})$ in the plot center to measure ear length, number of viable seeds and hollow seeds per ear, and mean values were regarded as variables per plant.

Field insects (rice planthopper and spider) on two randomly selected plants per plot and the rate of plants with white straws (RPW, representing C. suppressalis damage) to 16 center plants ( $\mathrm{HH}$ and/or $\mathrm{MH}$ ) were surveyed before harvesting at the Nanchang site. In Wuhan, insects were not surveyed due to the application of insecticides.

\section{Statistical analysis}

The mean values of all $\mathrm{HH}$ or $\mathrm{MH}$ plants per plot were used for statistical analysis. The data were $\log$-transformed to ensure a normal distribution of residuals. Split-plot ANOVA $\quad(\mathrm{Y} \sim$ Site $+\mathrm{I} \times \mathrm{P} \times \mathrm{D} \times \mathrm{T}+$ Error $\quad($ block $/ \mathrm{I} / \mathrm{P} / \mathrm{D}))$ 
was employed to test the effects of site (Wuhan vs. Nanchang), insect infection (I), percentage of HH plants (P), plant density (D) and plant types (T, HH vs. $\mathrm{MH}$ ). Due to significant site effects, split-plot ANOVA $(\mathrm{Y} \sim \mathrm{I} \times$ $\mathrm{P} \times \mathrm{D} \times \mathrm{T}+$ Error (block/I/P/D)) was used in Wuhan and Nanchang, respectively. Tukey's HSD test was used for multiple comparisons among percentages of $\mathrm{HH}$ plants.

To further investigate the differences between $\mathrm{HH}$ and $\mathrm{MH}$ individual plant biomass, relative to the $\mathrm{MH}$ performance in pure stand $T_{0}$, the relative differences $R D$ $=\left(R_{T i}-S_{T i}\right) / S_{T 0}$ were calculated (value at $T_{100}$ was calculated as $\left.R D=\left(R_{\mathrm{T} 100}-S_{\mathrm{T} 0}\right) / S_{\mathrm{T} 0}\right)$ [2]. $R D$ values were subject to a $t$-test to determine their deviation from 0 .

For replacement series analysis, the relative crowding coefficient (RCC) was calculated according to the equation in Ramachandran et al. [18]:

$$
\mathrm{RCC}=\left(\sum\left(\mathrm{R}_{\mathrm{Ti}} / \mathrm{S}_{\mathrm{Ti}}\right) / 3\right) /\left(\mathrm{R}_{\mathrm{T} 100} / \mathrm{S}_{\mathrm{T} 0}\right)
$$

where $\mathrm{R}_{T i}$ and $\mathrm{S}_{\mathrm{Ti}}$ are the biomass values for $\mathrm{HH}$ and MH respectively at percentage $T_{i}\left(T_{25}, T_{50}\right.$ and $\left.T_{75}\right)$ per unit area in the plot center. An RCC value of 1 indicates equal competitiveness between $\mathrm{R}$ and $\mathrm{S}$ plants. $\mathrm{RCC}>1$ indicates that $\mathrm{R}$ plants are more competitive than $\mathrm{S}$ plants and vise versa. A $t$-test was performed to determine whether the RCC values were significantly deviated from 1 .

As for biomass and full seed weight, a per-plot ANOVA $(\mathrm{Y} \sim \mathrm{I} \times \mathrm{D} \times \mathrm{P}+$ Error (block/I/D)), with block as a random factor and infection, density and percentage of $\mathrm{HH}$ plants as fixed factors, was carried out using the sum of the data of all $\mathrm{MH}$ and $\mathrm{HH}$ plants per plot, i.e. the whole population production. All statistic analyses were conducted in R software [51].

\section{Competing interest}

The authors declare that they have no competing interests.

\section{Authors' contributions}

YBL and JSL designed the study, carried out the experiment, analysed the data and wrote the manuscript; all authors contributed to the revisions. FG, YYL and GW provided field space for the experiment and involved themselves in the research. YBL and JSL provided funding, interpreted data and edited the manuscript. All authors read and approved the final manuscript.

\section{Acknowledgements}

This work was financially supported by the Special Program for New Transgenic Variety Breeding of the Ministry of Science and Technology, China (grant 2012ZX08011002), the National Environmental Protection Public Welfare Science and Technology Research Program of China (grant 201309038) and one Project of Chinese Research Academy of Environmental Sciences (2011YSKY-08).

\section{Author details}

'State Key Laboratory of Environmental Criteria and Risk Assessment, Chinese Research Academy of Environmental Sciences, Beijing 100012, China. ${ }^{2}$ State Key Laboratory of Integrated Management of Pest and Rodents, Institute of Zoology, the Chinese Academy of Sciences, 8 Dayangfang, Beijing 100101, China. ${ }^{3}$ Institute of Plant Protection, Jiangxi Academy of Agricultural Sciences, Nanchang 330200, China. ${ }^{4}$ Hubei Insect Resources Utilization and Sustainable Pest Management Key Laboratory, College of Plant Science and Technology, Huazhong Agricultural University, Wuhan 430070, China.
Received: 4 November 2014 Accepted: 13 April 2015

Published online: 26 April 2015

\section{References}

1. Stewart JCN, Halfhill MD, Warwick SI. Transgene introgression from genetically modified crops to their wild relatives. Nat Rev Genet. 2003;4(10):806-17.

2. Liu Y, Wei W, Ma K, Darmency H. Spread of introgressed insect-resistance genes in wild populations of Brassica juncea: a simulated in-vivo approach. Transgenic Res. 2013;22:747-56.

3. Warwick SI, Légère A, Simard MJ, James T. Do escaped transgenes persist in nature? The case of an herbicide resistance transgene in a weedy Brassica rapa population. Mol Ecol. 2008;17(5):1387-95.

4. Ellstrand N, Meirmans P, Rong J, Bartsch D, Ghosh A, de Jong T, et al. Introgression of crop alleles into wild or weedy populations. Annu Rev Ecol Evol Syst. 2013;44:325-45

5. Chen LJ, Lee DS, Song ZP, Suh HS, Lu BR. Gene flow from cultivated rice (Oryza sativa) to its weedy and wild relatives. Ann Bot. 2004;93:67-73.

6. Jank B, Rath J, Gaugitsch H. Co-existence of agricultural production systems. Trends Biotechno. 2006;24:198-200.

7. Demont M, Devos Y. Regulating coexistence of GM and non-GM crops without jeopardizing economic incentives. Trends Biotechnol. 2008;26(7):353-8.

8. Jongsma MA, Gould F, Legros M, Yang L, Loon JJA, Dicke M. Insect oviposition behavior affects the evolution of adaptation to Bt crops: consequences for refuge policies. Evol Ecol. 2010;24(5):1017-30.

9. Møldrup ME, Geu-Flores F, de Vos M, Olsen CE, Sun J, Jander G, et al. Engineering of benzylglucosinolate in tobacco provides proof-of-concept for dead-end trap crops genetically modified to attract Plutella xylostella (diamondback moth). Plant Biotechnol J. 2012;10(4):435-42.

10. Lu BR, Yang C. Gene flow from genetically modified rice to its wild relatives: Assessing potential ecological consequences. Biotechnol Adv. 2009;27(6):1083-91.

11. D'Hertefeldt T, Jorgensen RB, Pettersson LB. Long-term persistence of GM oilseed rape in the seedbank. Biol Lett. 2008:4:314-7.

12. van Heerwaarden J, Ortega Del Vecchyo D, Alvarez-Buylla ER, Bellon MR. New genes in traditional seed systems: Diffusion, detectability and persistence of transgenes in a maize metapopulation. PLoS One. 2012;7:e46123.

13. Hooftman DAP, Jong MJD, Oostermeijer JGB, Den Nijs HCM. Modelling the long-term consequences of crop-wild relative hybridization: a case study using four generations of hybrids. J Appl Ecol. 2007;44(5):1035-45.

14. Devos Y, Demont M, Dillen K, Reheul D, Kaiser M, Sanvido O. Coexistence of genetically modified (GM) and non-GM crops in the European Union. A review Agron Sustain Dev. 2009;29(1):11-30.

15. Hall L, Topinka K, Huffman J, Davis L, Good A. Pollen flow between herbicide resistant Brassica napus is the cause of multiple-resistant B. napus volunteers. Weed Sci. 2000;48:688-94.

16. Rong J, Song Z, Su J, Xia H, Lu B-R, Wang F. Low frequency of transgene flow from Bt/CpTI rice to its nontransgenic counterparts planted at close spacing. New Phytol. 2005;168(3):559-66.

17. Ellstrand NC. When transgenes wander, should we worry? Plant Physiol. 2001;125:1543-5.

18. Ramachandran S, Buntin GD, All JN, Raymer PL, Stewart Jr CN. Intraspecific competition of an insect-resistant transgenic canola in seed mixtures. Agron J. 2000;92:368-74.

19. Moon HS, Halfhill MD, Good LL, Raymer PL, Stewart Jr CN. Characterization of directly transformed weedy Brassica rapa and introgressed B. rapa with Bt cry1Ac and gfp genes. Plant Cell Rep. 2007;26(7):1001-10.

20. Yang X, Xia H, Wang W, Wang F, Su J, Snow AA, et al. Transgenes for insect resistance reduce herbivory and enhance fecundity in advanced generations of crop-weed hybrids of rice. Evol Appl. 2011;4(5):672-84.

21. Xia H, Lu B-R, Xu K, Wang W, Yang X, Yang C, et al. Enhanced yield performance of Bt rice under target-insect attacks: implications for field insect management. Transgenic Res. 2011;20(3):655-64.

22. Yang X, Wang F, Su J, Lu B-R. Limited fitness advantages of crop-weed hybrid progeny containing insect-resistant transgenes (Bt/CpTI) in transgenic rice field. PLoS One. 2012;7(7):e41220.

23. Wu KM, Lu YH, Feng HQ, Jiang YY, Zhao JZ. Suppression of Cotton Bollworm in Multiple Crops in China in Areas with Bt Toxin-Containing Cotton. Science. 2008;321(5896):1676-8. 
24. Hutchison WD, Burkness EC, Mitchell PD, Moon RD, Leslie TW, Fleischer SJ, et al. Areawide Suppression of European Corn Borer with Bt Maize Reaps Savings to Non-Bt Maize Growers. Science. 2010;330(6001):222-5.

25. Jhala AJ, Bhatt $H$, Topinka K, Hall LM. Pollen-mediated gene flow in flax (Linum usitatissmum L.): can genetically engineered and organic flax coexist? Heredity. 2011;106:557-66.

26. Langhof M, Hommel B, Hüsken A, Schiemann J, Wehling P, Wilhelm R, et al. Coexistence in maize: Do nonmaize buffer zones reduce gene flow between maize fields? Crop Sci. 2008;48(1):305.

27. Huang JK, Hu RF, Rozelle S, Pray C. Insect-resistant GM rice in farmers' fields: Assessing productivity and health effects in China. Science. 2005;308:688-90.

28. Chen LY, Snow AA, Wang F, Lu BR. Effects of insectresistance transgenes on fecundity in rice (Oryza sativa, Poaceae): a test for underlying costs. Am J Bot. 2006;93:94-101.

29. Xia H, Chen L, Wang F, Lu B-R. Yield benefit and underlying cost of insectresistance transgenic rice: Implication in breeding and deploying transgenic crops. Field Crops Res. 2010;118(3):215-20.

30. Tu J, Zhang G, Datta K, Xu C, He Y, Zhang Q, et al. Field performance of transgenic elite commercial hybrid rice expressing Bacillus thuringiensis S-endotoxin. Nat Biotechnol. 2000;18:1101-4.

31. Wang Y, Zhang G, Du J, Liu B, Wang M. Influence of transgenic hybrid rice expressing a fused gene derived from cry $1 A b$ and cry $1 A c$ on primary insect pests and rice yield. Crop Protect. 2010;29(2):128-33.

32. Wang F, Ye C, Zhu L, Nie L, Cui K, Peng S, et al. Yield differences between Bt transgenic rice lines and their non-Bt counterparts, and its possible mechanism. Field Crop Res. 2012;126:8-15.

33. Di K, Stewart Jr CN, Wei W, Shen B-C, Tang Z-X, Ma K-P. Fitness and maternal effects in hybrids formed between transgenic oilseed rape (Brassica napus L.) and wild brown mustard [B. juncea (L.) Czern et Coss.] in the field. Pest Manage Sci. 2009;65(7):753-60.

34. Escarré J, Lepart J, Sans X, Sentuc JJ, Gorse V. Effects of herbivory on the growth and reproduction of Picris hieracioides in the Mediterranean region. J Veg Sci. 1999;10:101-10.

35. Rogers W, Siemann E. Effects of simulated herbivory and resource availability on native and invasive exotic tree seedlings. Basic Appl Ecol. 2002;3(4):297-307.

36. Hawkes CV, Sullivan JJ. The impact of herbivory on plants in different resource conditions a meta-analysis. Ecology. 2001;82:2045-58.

37. Boalt E, Lehtilä K. Tolerance to apical and foliar damage: costs and mechanisms in Raphanus raphanistrum. Oikos. 2007;116(12):2071-81.

38. Vaughton G, Ramsey M. Seed mass variation in the shrub Banksia spinulosa (Proteaceae): resource constraints and pollen source effects. Int J Plant Sci. 1997; 158:424-31.

39. Wise MJ, Cummins JJ. Strategies of Solanum carolinense for regulating maternal investment in response to foliar and floral herbivory. J Ecol. 2006:94:629-36.

40. Weis $A E$, Hochberg ME. The diverse effects of intraspecific competition on the selective advantage to resistance: a model and its predictions. Am Nat. 2000;156:276-92

41. Haag JJ, Coupe MD, Chahill JF. Antagonistic interactions between competition and insect herbivory on plant growth. J Ecol. 2004;92:156-67.

42. Schardler M, Brandl R, Haase J. Antagonistic interactions between plant competition and insect herbivory. Ecology. 2007:88:1490-8.

43. Steets JA, Salla R, Ashman TL. Herbivory and competition interact to affect reproductive traits and mating system expression in impatiens capensis. Am Nat. 2006;167:591-600.

44. Vacher C, Weis AE, Hermann D, Kossler T, Young C, Hochberg ME. Impact of ecological factors on the initial invasion of Bt transgenes into wild populations of birdseed rape (Brassica rapa). Theor Appl Genet. 2004;109(4):806-14.

45. Alstad DN, Andow DA. Implementing management of insect resistance to transgenic crops. AgBiotech News Information. 1996;8:177-81.

46. Lu Y, Wu K, Jiang Y, Xia B, Li P, Feng H, et al. Mirid Bug Outbreaks in Multiple Crops Correlated with Wide-Scale Adoption of Bt Cotton in China. Science. 2010;328(5982):1151-4

47. Bergelson J, Purrington CB. Surveying patterns in the cost of resistance in plants. Am Nat. 1996;148:536-58.

48. Kalinina O, Zeller SL, Schmid B. Competitive performance of transgenic wheat resistant to powdery mildew. PLoS One. 2011;6:e28091.
49. Damgaard C, Kjaer C. Competitive interactions and the effect of herbivory on Bt-Brassica napus, Brassica rapa and Lolium perenne. J Appl Ecol. 2009;46(5):1073-9.

50. Liu Y, Wei W, Ma K, Li JS, Liang Y, Darmency H. Consequences of gene flow between oilseed rape (Brassica napus) and its relatives. Plant Sci. 2013;211:42-51.

51. R Development Core team. R: A language and environment for statistical computing. V. R foundation for statistical computing, Austria. 2008; http:// www.r-project.org/ (Ed.).

\section{Submit your next manuscript to BioMed Central and take full advantage of:}

- Convenient online submission

- Thorough peer review

- No space constraints or color figure charges

- Immediate publication on acceptance

- Inclusion in PubMed, CAS, Scopus and Google Scholar

- Research which is freely available for redistribution 